\title{
IRIDA syndrome
}

INSERM

\section{Source}

INSERM. (1999). Orphanet: an online rare disease and orphan drug data base. IRIDA syndrome. ORPHA:209981

IRIDA (Iron-refractory iron deficiency anemia) syndrome is a rare autosomal recessive iron metabolism disorder characterized by iron deficiency anemia (hypochromic, microcytic) that is often unresponsive to oral iron intake and partially responsive to parenteral iron treatment. 